antitoxin and eight 500 units. His conclusion was as follows :

“A few children showed a positive reaction as early as the seventh day. Most of them, however, did not react positively till eighteen to twenty-eight days after the injection, one reacting negatively for forty-six days. No difference was noticed in this respect between those receiving 500 units and those receiving twice that amount."

The results of this investigation, as far as they go, correspond more nearly to those of the present study. Its value, however, is limited by the small number of patients tested.

\section{Present Investigation}

This was carried out on scarlet fever patients in the L.C.C. North-Western Hospital, in whom the occurrence of sporadic cases of diphtheria had been giving rise to some anxiety. These were Schick-tested on admission, and, of those thus tested, 104 consecutive Schick-positives were included in this investigation. No patient in whom the reaction was in any way doubtful was taken. Of the 104, four were removed from the hospital or transferred to another ward after developing a cross-infection other than diphtheria before Schick-retesting, so that the records of exactly 100 cases form the basis of this report.

Each of these received 500 units of antitoxin subcutaneously, as soon as possible after it had been determined that the Schick test was positive, and generally about the fourth day after admission to hospital. On the fourteenth day after injection a Schick re-test was carried out, followed, on the twenty-first day, by a second re-test. Both re-tests were read on the third and on the tenth day in order that there might be no doubt about the readings. Assuming the Schick test to be an accurate criterion of immunity, this method would show the numbers immune at fourteen and at twenty-one days after the injection of antitoxin. Taking the 100 cases as a whole the following results were obtained:

$\begin{array}{cccccr}\text { Immune after fourteen days } & \ldots & \ldots & \ldots & 89 \\ \text { Immune after fourteen days, but } & \text { not } & \text { re-tested } & \text { at } & \\ \text { twenty-one days } \ldots & \ldots & \ldots & \ldots & \ldots & 9 \\ \text { Immune after twenty-one days } & \ldots & \ldots & \ldots & \mathbf{8 4} \\ \text { Not immune at fourteen days } & \ldots & \ldots & \ldots & 2\end{array}$

Thus, of those fully tested, five who were immune after fourteen days lost their immunity before the twenty-first day, Of the nine cases where the final re-test was not, for various reasons, carried out, it may be assumed that they would have divided in somewhat the same proportion as those who were fully tested-that is, in the proportion of 84 to 5 . Whether they are divided on this basis and introduced into the table or are ignored for statistical purposes the effect is the same. Immunity lasted for at least twenty-one days in 92.3 per cent., for at least fourteen days in a further 5.6 per cent. (a total of 97.9 per cent.), and only 2.1 per cent. were not immune after fourteen days.

If the results are analysed into age groups further interesting points appear.

\begin{tabular}{ccc|c|c|c|c}
\hline \multicolumn{1}{c|}{ Age } & & $\begin{array}{c}\text { Immune at } \\
14 \text { days }\end{array}$ & $\begin{array}{c}\text { Immune at } \\
\text { 21 days }\end{array}$ & $\begin{array}{c}\text { Not Immune } \\
\text { at 14 days }\end{array}$ & Total \\
\hline Under 5 years & $\ldots$ & $39(5)$ & 33 & 0 & 39 \\
$5-10$ years & $\ldots$ & $\ldots$ & $47(2)$ & -42 & 0 & 47 \\
$10-15$ years & $\ldots$ & $\ldots$ & $10(1)$ & 8 & 1 & 11 \\
Adult ... & $\ldots$ & $\ldots$ & $2(1)$ & 2 & 1 & 3 \\
\hline
\end{tabular}

The figures in parentheses in the first column are the numbers of those who were re-tested after fourteen days but not after twenty-one days. It will be noticed that all the patients under 10 years were immune after fourteen days, and, ignoring the incompletely tested, only four of these lost their immunity between the fourteenth and the twenty-first day. Of the 10 to 15 age group one out of eleven was not immune after fourteen days, and one other lost the immunity before the twenty-first day:

The effect of antitoxin on that ever-present annoyance in scarlet fever wards, the Klebs-Loeffler-bacillus-positive nasal discharge, is also worth recording. In the 100 cases under observation six developed this complication, but it is important to note that in none of them did it develop within four weeks from the date of immunization, the actual intervals being twenty-eight, twenty-nine, thirty, forty-three, forty-eight, and sixty-six days. Virulent strains of the organism were isolated from four of these cases after the intervals named.

\section{Conclusions}

Passive immunity to diphtheria was obtained in a highly satisfactory proportion (97.9 per cent. of all cases and 100 per cent. of those under 10 years) of Schickpositives by the injection of $\mathbf{5 0 0}$ units of diphtheria antitoxin. In adults and adolescents over 15 a larger dose is probably necessary. The duration of this immunity is at least fourteen days, and in the majority of cases $\mathbf{9 4 . 4}$ per cent.) extends to twenty-one days. The incidence of diphtheritic infection in passively immunized patients occurring at the times stated would suggest that it is unwise to regard this form of immunity as lasting longer than three weeks.

These results are published by the permission of Dr. A. Joe, medical superintendent of the hospital, to whom we are indebted for advice and assistance.

\section{References}

1 Kolmer and Moshage: Amer. Journ. Dis. of Child., ix, 189.

2 Zuckerman: New York Med. Journ., ii, 808.

\section{HEARTBURN IN PREGNANCY \\ BY \\ E. BRIAN RAYNER, M.B., Сн.B.}

It is with considerable trepidation that $I$, a minnow among the tritons, venture to record some observations upon heartburn in pregnancy-a condition which is dismissed in the textbooks with a few words, but which is a frequent source of tribulation to the general practitioner, and may become a veritable nightmare to the patient.

My attention was first directed to this condition in the ante-natal department of the Royal Simpson Maternity Hospital, Edinburgh, where one was seeing a large number of patients suffering from very distressing heartburn which did not respond to the routine treatment with so-called anti-acid mixtures. It was while attempting to correlate the various symptoms associated with hypoacidity in non-pregnant patients in another ward* that a clue to the solution of the problem appeared. The interesting and surprising fact emerged that a certain number of patients suffering from hypo-acidity com-

* I am indebted to Dr. John Eason of the Royal Infirmary, Edinburgh, for permission to scrutinize a series of case records where hyposecretion had been proved by test meal. 
plained of heartburn - a symptom which is ascribed in the textbooks to those patients.suffering from hyperacidity or peptic ulcer.

It occurred to me that possibly many pregnant women with heartburn might have been wrongly labelled as sufiering from hyperacidity, and should, in fact, be regarded as suffering from hypo-acidity. I determined upon a therapeutic test of my theory by administering acid. hydrochlor. dil. to these women. Permission to make the experiment was obtained from Dr. E. Chalmers Fahmy, by whose courtesy I was attending the department, and to whom I am very grateful for encouragement and help. It was resolved to attempt the treatment on only the worst and most intractable cases, and the history of the first patient is worth recording individually as being typical of the majority.

Mrs. M., two-para, seven months pregnant, complained of very severe heartburn, aggravated by leaning forward or by greasy food. The heartburn was very much worse in bed at night, and kept her awake. She vomited every night. Duration: since the third month. She had tried bicarbonate of soda and other alkalis without avail. She was given 30 minims of acid. hydrochlor. dil., divided into two doses with each meal. She returned after one week very much improved, and at the end of fourteen days her heartburn had completely disappeared, but reappeared if she stopped the medicine. She was no longer vomiting, was sleeping well, and she volunteered the remark that she "felt better than she had done during the whole of the rest of the pregnancy," or during her previous pregnancies, throughout which she had suffered from heartburn.

\section{REVIEW OF MATERIAL}

The cases recorded below were partially collected in the ante-natal department of the hospital, where, owing to exigencies of time, the number treated was small, and partly in general practice, where the accumulation of cases is obviously a slow business. In none of the patients included in the series were any of the other toxaemias of pregnancy present. In each case the patient was advised to abstain from all greasy foods, and the bowels were regulated where necessary. Two doses of acid. hydrochlor. dil., varying from 10 to 20 minims each, were given with every meal, well diluted and flavoured with orange juice (if necessary), the usual procedure being to take one dose during the meal and the other twenty minutes after the meal.

In a series of forty-five cases the patients were divided into three groups.

Group I.-Those that were not relieved by alkalis but were relieved by acid.

Group II.-Those that were relieved by alkalis in relatively small quantities (as compared with the large quantities given to patients with gastric or duodenal ulcer).

Group III.-Those whose condition was aggravated by acid and not relieved by alkalis, as in Group II.

The results were: Group I, thirty-four ; Group II, five ; Group III, six.

It is undoubtedly more satisfactory to draw conclusions from experimental data, and thence to put theory to the test of clinical practice. These notes would admittedly be more valuable if they included a record of test meals taken from these patients. Pregnant women willing to undergo this test are few and far between, especially in general practice. Perhaps a bolder man than I will supply the deficiency. It cannot, however, be denied that the results raise several points of interest, possibly the more interesting because we must work backward from clinical results to theories.

1. Why do patients suffering from either hyperacidity or hypo-acidity - both, in certain cases-complain of heart- burn? A possible explanation is that the stomach has a large safety margin for gastric secretions normally present during digestion, and only reacts when that margin is overstepped, as in gross hyperacidity. Conversely there may be a relatively small margin for substances not normally present during digestion-for example, excessive mucus, products of fermentation, fatty acids, etc. When this margin is overstepped the stomach again reacts. In many hyperacid and in some hypo-acid stomachs, the earliest reaction takes the same form-namely, heartburn.

2. What is the explanation for the three groups of cases? It is suggested that the patients in Group I are suffering from a genuine hypo-acidity. Those in Group II from mucous gastritis, and the essential action of the so-called antacid is, on the contrary, the dissolution of mucus and stimulation of secretion. Those in Group III are suffering from genuine hyperacidity, and should be treated on the same lines as any other patient with this condition. It may even become necessary to carry this as far as a rigorous ulcer regime. In this connexion it was discovered that two of the patients in Group III had been treated for gastric ulcers some years earlier.

3. In a large proportion of patients in Groups I and II the condition is very much worse at night (in many cases keeping the patient awake), is aggravated by a meal containing a large proportion of fat, or by stooping down. It is relieved in some cases by vomiting. One ventures to suggest: (1) that symptoms are worse at night owing to the accumulation of fermenting material throughout the day, stasis being aided in many cases by increased intraabdominal pressure ; (2) that a fatty meal tends to decrease the secretion of acid; and (3) that a vomit is a physiological stomach washout-the treatment par excellence of mucous gastritis. It is a proved fact that anxiety and worry diminish the gastric secretion. It would appear, therefore, that many of these patients establish a vicious circle for themselves - they come to dread the meals on account of the heartburn that follows them, thereby sitting down to the table with a physiological hyposecretion. The administration of dilute hydrochloric acid breaks the circle and restores confidence.

4. Heartburn occurs throughout pregnancy, though many do not come for treatment until about the sixth month, and many do not come at all. (This fact became obvious during the investigation, but, for the sake of simplicity, the exact figures have not been given.)

\section{Conclusions}

1. Heartburn is regarded as a trivial matter because it does not endanger the patient's life ; but it is a far from trivial matter for the patient, or for the general practititioner who has to cope with it. It certainly occurs a great deal more frequently than the major toxaemias of pregnancy.

2. It has been wrongly regarded in the past as a symptom of hypersecretion. It is suggested that it may equally well be a symptom of hyposecretion or mucous gastritis.

3. The use of acid. hydrochlor. dil. with meals will clear up many otherwise intractable cases of heartburn, and should always be given a trial.

4. It is freely admitted that nowadays it is unusual to work backwards from results to causes. One's methods may be faulty and one's reasoning fallacious, but it can at least be said that the results, especially in general pract:ce, have amply justified the experiment. One's defence must be the circumstances in which this work was carried out, and one can only hope that these observations may serve as a sprat to catch a mackerel-or, to return to my original metaphor, a minnow to catch a triton. 